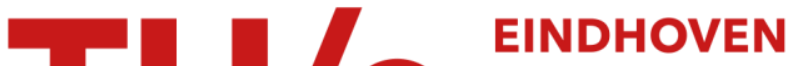 UNIVERSITY OF TECHNOLOGY
}

\section{A survey of techniques applied to non-stationary waveforms in electrical power systems}

\section{Citation for published version (APA):}

Rodrigues, R. P., Silveira, P. M., \& Ribeiro, P. F. (2010). A survey of techniques applied to non-stationary waveforms in electrical power systems. In Proceedings of the 14th International Conference on Harmonics and Quality of Power (ICHQP 2010), 26-29 September 2010, Bergamo, Italy (pp. 1-8). Institute of Electrical and Electronics Engineers. https://doi.org/10.1109/ICHQP.2010.5625503,

https://doi.org/10.1109//CGQP.2010.5625503

\section{DOI:}

10.1109/ICHQP. 2010.5625503

10.1109/ICGQP.2010.5625503

\section{Document status and date:}

Published: 01/01/2010

\section{Document Version:}

Publisher's PDF, also known as Version of Record (includes final page, issue and volume numbers)

\section{Please check the document version of this publication:}

- A submitted manuscript is the version of the article upon submission and before peer-review. There can be important differences between the submitted version and the official published version of record. People interested in the research are advised to contact the author for the final version of the publication, or visit the $\mathrm{DOI}$ to the publisher's website.

- The final author version and the galley proof are versions of the publication after peer review.

- The final published version features the final layout of the paper including the volume, issue and page numbers.

Link to publication

\section{General rights}

Copyright and moral rights for the publications made accessible in the public portal are retained by the authors and/or other copyright owners and it is a condition of accessing publications that users recognise and abide by the legal requirements associated with these rights.

- Users may download and print one copy of any publication from the public portal for the purpose of private study or research.

- You may not further distribute the material or use it for any profit-making activity or commercial gain

- You may freely distribute the URL identifying the publication in the public portal.

If the publication is distributed under the terms of Article 25fa of the Dutch Copyright Act, indicated by the "Taverne" license above, please follow below link for the End User Agreement:

www.tue.nl/taverne

Take down policy

If you believe that this document breaches copyright please contact us at:

openaccess@tue.nl

providing details and we will investigate your claim. 


\title{
A Survey of Techniques Applied to Non-stationary Waveforms in Electrical Power Systems
}

\author{
R.P. Rodrigues, P.M. Silveira, Member, IEEE, and P.F. Ribeiro, Fellow, IEEE
}

\begin{abstract}
The well-known and ever-present time-varying and non-stationary nature of waveforms in power systems requires a comprehensive and precise analytical basis that needs to be incorporated in the system studies and analyses. This timevarying behavior is due to continuous changes in system configurations, linear load levels and operating modes of nonlinear load / equipment and thus present conceptual and practical challenges. The objective of this paper is to provide a comprehensive bibliographical survey of the proposed techniques to deal with time-varying and non-stationary waveforms in power systems.
\end{abstract}

Index Terms-- Non-stationary Waveforms, Time-Frequency Analysis, Time-Varying Waveforms, Signal Processing.

\section{INTRODUCTION}

$\mathrm{N}$ on-stationarity is a concept far from being a new subject in the context of signal processing. It is an extremely common concept among areas of seismology, acoustic and other areas of research, where non-stationary signals are part of the scenario. However, when treated in the context of the electric power systems and their voltage and current waveforms, such a concept exposes an area of studies which is not yet widely exploited and which is open for new ideas and techniques.

The electric power systems have expanded as a response to the necessity of providing energy to an also growing number of consumers, which have new devices and equipment to be connected to the electric grid. An increasing number of these new equipment operate in a non-linear way, and thus they produce the so-called harmonic distortion [1]. Besides, some of these devices have distinct cycles of operation which give rise to a time-dependent harmonic pollution. Thus, this class of equipment has contributed significantly to the propagation of time-varying harmonic in the power systems.

The main causes of non-stationary distortions in power systems are: (i) load fluctuation involved in the actual phase of operation of equipments; (ii) demand level variation, and (iii) upstream system modifications at point-of-common coupling

This work was supported in part by CNPq, CAPES and FAPEMIG (brazilian research agencies). R.P. Rodrigues and P.M. Silveira are with Itajubá Federal University / Power Quality Study Group, Brazil (e-mails: rprodrigues@unifei.edu.br and pmsilveira@unifei.edu.br, respectively). P.F. Ribeiro is with Calvin College, USA, and Technical University of Eindhoven, Netherlands (e-mail: pfribeiro@ieee.org).
(PCC) as consequence of upstream load or system impedance variation [2], [3].

One of the most important techniques used in power quality studies is the Fourier Transform. However, when applied to analyze non-stationary data, it becomes evident their limitations [4]-[7]. As a consequence, there is the necessity of developing new techniques capable of offering proper handling and understanding of non-stationary waveforms. As response to this necessity, different approaches with application, functions, advantages, and limitations are found in the literature.

In this context, the objective of this paper is to bring a critical review of the proposed techniques found in the literature, and whose purposes are to address the gaps left by Fourier Series and Transform.

In this paper the limitations of the Fourier Transform are mentioned in Section II. In Section III the different methods found in the literature and proposed to be used in the analysis of non-stationary waveforms distortions in electric power system are presented, and in Section IV general conclusions are made.

\section{FOURIER TRANSFORM AND NON-STATIONARITY}

One of the primary assumptions behind the Discrete Fourier Transform (DFT) is the stationarity of the signal to be represented [4]-[9]. As a consequence, the Fourier spectrum defines uniform harmonic components in a global sense [5]. This leads to the use of base functions with infinite support and then makes the decomposition of the signal in analysis occur over a set of functions that exist through the entire line of real numbers (i.e. they do not vanish when $t \rightarrow \infty$ or $t \rightarrow-\infty)$. Such a characteristic provides erroneous representation of non-stationary signals since none of them have a global uniformity [5]. As a final consequence, a spread of the energy content of the original signal occurs over a wide range of frequencies that are not real components of the original signal.

The next two examples illustrate limitations of the DFT when applied to time-varying signals. The first one exemplifies the spread of energy over non-real harmonic components when a pure sinusoidal waveform is submitted to exponential amplitude variation, dictated by (1) and traced in Fig. 1(a). The variation of amplitude cannot be properly handled by the Fourier transform and, as a consequence, 
components other than the real fifth harmonic, shown in Fig. 1(b), are used by the transformation to accommodate the nonuniformity present in the probe signal.

$$
y_{a}(t)=e^{-18 t} \sin \left(5 \omega_{\mathrm{o}} t\right)
$$

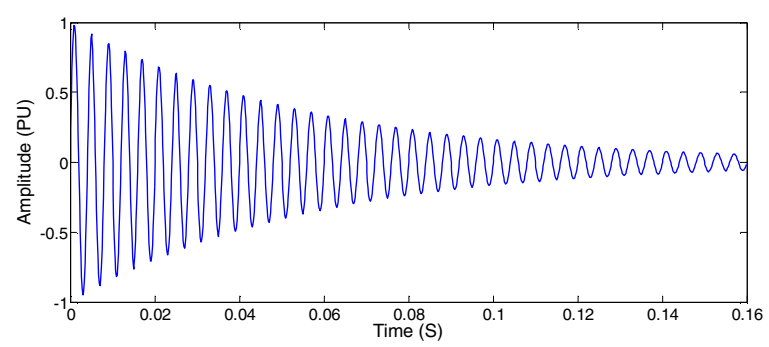

(a)

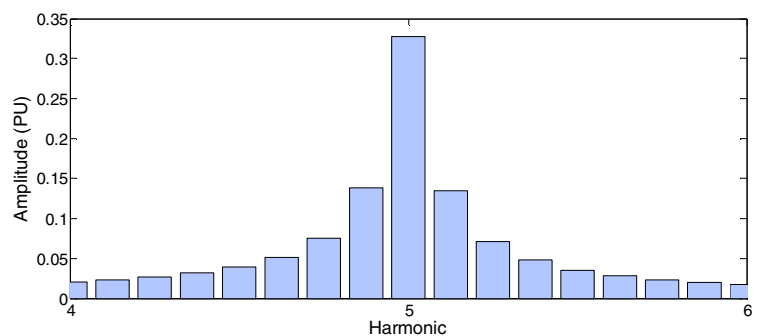

(b)

Fig. 1. Waveform with exponential amplitude variation (a) and the portion of its spectrum (b) with the greatest concentration of energy.

The second example shows the response of the DFT to a signal with a small linear frequency variation from $-2 \%$ to $+2 \%$ and modeled by (2), which generates the signal in Fig. 2(a). Figure 2(b) clearly exposes that such a variation in frequency, even small, is not correctly interpreted by the DFT, providing erroneously other frequency components.

$$
y_{f}(t)=\sin \left(\omega_{\mathrm{o}}(0.92+0.250 t) t\right)
$$

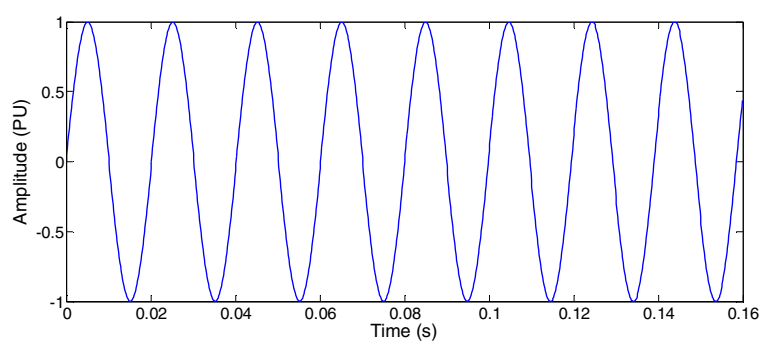

(a)

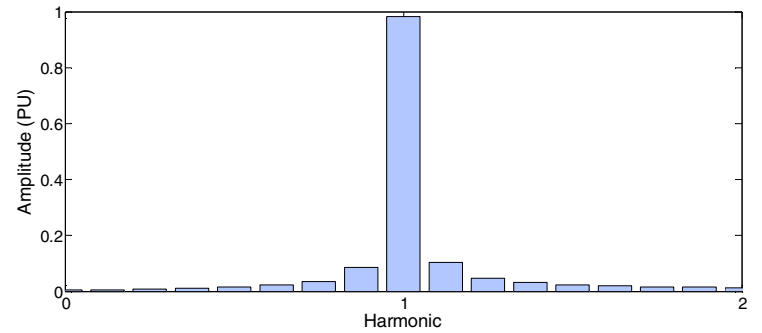

(b)

Fig. 2. Waveform with linear frequency variation from $-2 \%$ to $2 \%$ of the initial frequency (a) an the principal portion of its spectrum (b).

In a quantitative perspective, the spread of energy over non-real components is approximately $38 \%$ for the first test and about $11 \%$ for the second probe signal.

In conclusion, the DFT is not capable of properly handling time-varying signals. Besides, this transformation does not provide temporal reference, which is another negative point in the context of non-stationary data.

\section{ANALYSIS OF NON-STATIONARY WAVEFORMS}

There are several methods presented in the literature to deal with non-stationary signals in electric power systems. They are summarized in Table 1.

TABLE I

CLASSES OF METHODS FOR ANALYSIS OF NON-STATIONARY SigNALS IN ELECTRICAL POWER SYSTEMS

\begin{tabular}{|l|l|l|}
\hline Class - Concept & Sub-class & References \\
\hline Specific concepts & $\begin{array}{l}\text { generalized concept of } \\
\text { frequency and evolutionary } \\
\text { spectra }\end{array}$ & {$[10]-[12]$} \\
\cline { 2 - 3 } & group of frequencies/energies & {$[4],[13]$} \\
\hline \multirow{4}{*}{$\begin{array}{l}\text { rime-frequency } \\
\text { representations }\end{array}$} & short-time Fourier transform & {$[6],[24]-[26]$} \\
\cline { 2 - 3 } & Wavelet transform & {$[18],[28]-[30]$} \\
\cline { 2 - 3 } & S transform & {$[32],[33]$} \\
\cline { 2 - 3 } & others & {$[34],[35]$} \\
\hline state estimation & Kalman filtering & {$[44]-[50]$} \\
\cline { 2 - 3 } & others & {$[54],[56],[57]$} \\
\hline \multirow{2}{*}{$\begin{array}{l}\text { digital signal } \\
\text { processing }\end{array}$} & phase-locked loop & {$[58],[60]-[62]$} \\
\cline { 2 - 3 } & filters and classic filter banks & {$[63],[64]$} \\
\cline { 2 - 3 } & adaptive notch filter & {$[66]$} \\
\cline { 2 - 3 } & empirical mode decomposition & {$[35],[72]$} \\
\hline parametric and parametric-like approaches & {$[75]-[78]$} \\
\hline \multicolumn{2}{|c|}{ artificial inteligence } & {$[81]-[83]$} \\
\hline
\end{tabular}

\section{A. Specific Concepts}

Two main categories of concepts specifically related to the non-stationary scenario are presented in the literature. The first one is formed by the generalized concept of frequency (GCF) and the concept of evolutionary spectra (ES) [10], [11]. GCF states that in the presence of a non-stationary function, the maximum absolute frequency occurs in $\omega_{o}$, the so-called generalized frequency of such a function. Then, this function may be locally modeled as a sine wave with the given generalized frequency $\omega_{o}$ and a smoothly varying amplitude. The ES concept is useful to represent the distribution of energy over the frequencies present in a signal in a given instant of time, while the stationary spectra is related to the distribution of energy for the entire process, i.e., in any instant of time. Applications of the concept of ES can be found in [11], [12], where time-frequency representations are developed.

The second category is represented by the concept of groups of frequencies. This concept encompass the idea of using a band of frequencies centered on a specific harmonic instead of the own harmonic. It is applied in [4], [13] to the measurement of the energy related to the group of harmonics and good results are obtained, but limitations related to the measurement of sub-harmonics and harmonics that are far enough from the harmonic frequencies exist. Due to its main idea, this concept is clearly not suitable to track parameters of individual time-varying components. 


\section{B. Time-frequency Representations}

Time-frequency representations (TFR) compose a class of techniques whose intention is to construct joint time and frequency representations of signals in a way that spectral components and its variations may have a temporal reference. Classical members of such a class are the Wigner-Ville distribution (WVD) [14] and the Short-Time Fourier Transform (STFT), but the WVD displays cross-terms when multi-component signals are analyzed [15] and the STFT has a serious tradeoff between time and frequency resolutions [16], among others problems inherited from the DFT [4]. Numerous approaches aimed at developing new TFR or at improving the already existent are found in the literature [12], [15]-[23].

Regarding the STFT-based methods, Table 2 presents a summary encompassing the most important proposals, their limitations and main characteristics. In [6], for example, a method based on the formulas derived from the analysis of errors of the DFT is present and good results are archived, but the proposed tracking is focused only on the fundamental component. In [24], a sliding-window recursive DFT is proposed and it is further improved in [25] by the usage of a downsampling operator before the extraction of each group of harmonics to be analyzed. Good results are presented in [24] and better ones in [25], but both proposals are vulnerable to frequency variation and interharmonics. In [26], a hybrid method that uses both STFT and Wavelet Multi-resolution Analysis (MRA) [27] is proposed to the study of transient waveforms. The main idea is to decompose the transient signal in groups of energy and then apply the STFT only to the groups related to the transients. Nevertheless, even with such a prior separation, the method inherits the known problems of the STFT when the analysis of transients [4], [6], [7] must be executed.

TABLE 2

STFT-BASED METHODS

\begin{tabular}{|l|l|}
\hline Ref. & Proposal and characteristics \\
\hline$[6]$ & $\begin{array}{l}\text { - tracking of frequency and phasors; } \\
\text { - limited to fundamental component; } \\
\text { - better results than the original DFT; } \\
\text { - higher computation effort than the DFT. }\end{array}$ \\
\hline$[24]$ & $\begin{array}{l}\text { - tracking of individual waveforms; } \\
\text { - based on sliding-window recursive DFT; } \\
\text { - no phase delay [25]; } \\
\text { - vulnerable to frequency variation and interharmonics; } \\
\text { - better results than the original DFT. }\end{array}$ \\
\hline$[26]$ & $\begin{array}{l}\text { - analysis of transient waveforms; } \\
\text { - uses the DWT and the STFT; } \\
\text { - applies the concept of group of harmonics; } \\
\text { - inherits the limitations of the STFT; } \\
\text { - higher computation effort than the DFT. }\end{array}$ \\
\hline
\end{tabular}

More specific applications of the wavelet transform can be found in [28], where a method based on wavelet transform associated with LMS (least mean squares), as well as with RLS (recursive least squares) algorithm to track non-stationary harmonics in real-time is proposed. The LMS algorithm provides an accurate response with a small transient time when a signal-noise model is used. But, with the same signal the RLS-based version has some drawbacks related to the accuracy and to transient time. In [18], a method which uses both DWTP (discrete wavelet package) and CWT (continuous wavelet transform) to extract harmonic parameters is proposed. The method is aimed at identifying harmonic trends in non-stationary waveforms and implements an algorithm to mitigate the problems related to the imperfect frequency response of the filters employed by the wavelet transform [27]. The results reported show that the proposed method is able to identify harmonic trends with improvements. In [29], a comprehensive tutorial on using wavelet and MRA in the analysis of non-stationary waveforms is shown, and, in [30], a simple example utilizing the Morlet wavelet as visualizing tool for non-stationary harmonics in power systems is presented.

As an extension of the CWT which provides phase information, the S transform (ST) [31] is other type of timefrequency representation applied to the analysis of nonstationary waveforms in electric power systems. This transformation has some characteristics directly inherited from the wavelet transform, and since it employs non-orthogonal decomposition base functions (i.e. generates redundant information), it is more suitable to the analysis of fast transients. A tutorial on ST employment in the detection of power quality events is shown in [32] and, in [33], this transformation is used together with fuzzy logic in a recognition system for power quality events. In [34], the Gabor transform (GT) is used to analyze harmonic trends providing good results. Some limitations related to the accuracy suggest further studies of its application. In [35], the application of the Hilbert transform (HT) is carried out as part of the method called Empirical Mode Decomposition (EMD), which is further discussed within a specific session.

Table 3 shows a summary [36] that outlines the applications and limitations of STFT, DWT, and ST.

TABLE 3

STFT, DWT, AND ST APPLICATIONS AND LIMITATIONS

\begin{tabular}{|l|l|l|}
\hline TFR & Applications & Limitations \\
\hline STFT & $\begin{array}{l}\text { - tracking of time- } \\
\text { varying harmonics. }\end{array}$ & $\begin{array}{l}\text { - inherits the problems of the DFT; } \\
\text { - its fixed time resolution make it } \\
\text { not suitable for non-stationary } \\
\text { waveforms with both high and low } \\
\text { frequency components. }\end{array}$ \\
\hline DWT & $\begin{array}{l}\text { - disturbance detection; } \\
\text { - event classification; } \\
\text { - time-varying transient } \\
\text { harmonics } \\
\text { measurement. }\end{array}$ & $\begin{array}{l}\text { - its accuracy may not be enough } \\
\text { for some classes of analysis and } \\
\text { measurements; } \\
\text { - suffers from frequency spillover } \\
\text { in its application filters. }\end{array}$ \\
\hline ST & $\begin{array}{l}\text { - event detection; } \\
\text { - event classification. }\end{array}$ & $\begin{array}{l}\text { - provides poor resolution at high } \\
\text { frequencies; } \\
\text { - generates redundant information } \\
\text { that difficult the analysis of its } \\
\text { results. }\end{array}$ \\
\hline
\end{tabular}

Others representations present in literature that do not have yet applications in power systems, but that propose techniques that may be part of future investigations in the area addressed by this paper may be found in [37]-[41].

\section{State Estimation}

State estimation techniques proposed to handle nonstationary waveform distortions in power systems are mainly 
related to the application of so-called Kalman filtering (KF) [42]. According to [43], this class of techniques is capable of track rapidly varying process, is suitable for recursive estimation of process parameters, and it is known to be an optimal estimator for linear dynamic systems with white process and measurement noises.

One of the first techniques proposing the employment of $\mathrm{KF}$ as an analysis tool for non-stationary waveforms in power systems is presented in [44], where it is intended for the estimation of phasors and frequency drifts, but the work is clearly an initial approach restricted to the tracking of the fundamental component since the results shown make it clear that further investigations were necessary. In [45], a more elaborated state-space signal model which incorporates harmonic waveforms, its amplitude variations and process noise, but no frequency variation, is considered. The results related to the tracking of non-stationary data clearly expose the ability of the proposed method to track signals variations, but since the analyzed signals are recorded ones, it is not possible to state about its accuracy. In [46], the employment of complex KF and transform are done to track frequency variations in the presence of harmonic distortions and white noise in 3-phase systems. The reported results are quite good even in the presence of amplitude variations and step and linear changes in the frequency. A didactic approach about the methodology of application of KF-based state observers to track non-stationary signals in power systems and its application to the estimation of fault current and voltage amplitude are presented in [47]. In [48], results of analytical and empirical experiments based on a linear estimation model for dynamic phasors and symmetric components are present. The related approach is extended to polyphase systems and the results reported are more accurate than the application of STFT. Another technique whose purpose is to estimate only the fundamental component is proposed in [49], where a specific method is employed to estimate the frequency of the signal and this frequency is used to update the estimation of amplitude executed by a Kalman filter. The results show that the method is robust to variation in the frequency and to the presence of harmonics, but it suffers from erroneous transient response in the estimation of amplitude when step changes in the frequency are introduced. A more recent proposal is brought in [50]. This work develops an extension to the method which uses the real model of the Kalman filters and has the objective of tracking non-stationary harmonic waveforms. Such an extension uses the Taylor series to improve the signal model employed by the filters, adds a reset mechanism to minimize the temporal tracking errors, and is also robust to deviations in the fundamental frequency. The results reported shows significant improvements if the method proposed is compared to others Kalman filters models in the tracking of frequency, amplitude an phase under variations in frequency and amplitude.

Table 4 brings the most relevant characteristics and tracking capabilities of the principal KF-based methods analyzed.
TABLE 4

KF-BASED METHODS

\begin{tabular}{|l|l|l|}
\hline Ref. & Tracking capabilities & Characteristics \\
\hline$[44]$ & $\begin{array}{l}\text { frequency drift and } \\
\text { amplitude }\end{array}$ & $\begin{array}{l}\text { restricted to the fundamental } \\
\text { component }\end{array}$ \\
\hline$[49]$ & amplitude and phase & susceptible to frequency variations \\
\hline$[45]$ & amplitude and phase & applied to 3-phase systems \\
\hline$[46]$ & frequency & $\begin{array}{l}\text { suitable to polyphase systems and } \\
\text { susceptible to frequency variations }\end{array}$ \\
\hline$[48]$ & $\begin{array}{l}\text { dynamic phasors and } \\
\text { symmetric components }\end{array}$ & $\begin{array}{l}\text { higher computational effort than } \\
\text { related KF models }\end{array}$ \\
\hline$[50]$ & $\begin{array}{l}\text { amplitude, phase and } \\
\text { frequency }\end{array}$ & \multicolumn{2}{|l}{} \\
\hline
\end{tabular}

It is important to report that the conventional KF models are optimal Bayesian methods that employ linear systems models to predict the probabilistic density function ( $\mathrm{pdf}$ ) from a measuring time to the next [51], and that they require the process and measurement noises to be Gaussian distributed. Thus, in situations where Gaussian noise distributions and linearity may not be claimed, conventional KF does not provide optimal estimations. Some proposals of methods that were not applied to the subject of this paper but are also developed to work with non-stationary harmonics in scenarios where conventional KF is not suitable may be found in [52], [53].

Non KF-based state estimation techniques designed to handle non-stationary waveforms in electrical systems can also be found in [54], [56], [57]. In [54], an approach based on weighted least absolute value dynamic filtering (WLAV) [55] to on-line track non-stationary harmonics is presented, but the resultant accuracy suggests the need of further improvement and a heavy susceptibility on frequency drift. Better results are shown in [56], where the estimation of frequency and amplitude is proposed through the employment of a prediction error minimization algorithm based on the method of Gauss-Newton. According to the tests brought by the proposed approach, the method proved to be fast and capable of correctly track frequency and amplitude variations, but an analysis of the related application algorithm suggests higher computational effort than KF-based approaches. In contrast, in [57] a proposal based on ellipsoidal set-theoretic methods in company with an optimal reduced-order estimator is presented and is focused in a reduction of computational effort. The results show that the proposed method has similar performance to full-order alternatives, but it only contemplates the tracking of amplitude, have some accuracy issues and is susceptible to frequency drifts.

\section{Signal Processing}

Signal processing techniques applied to the analysis of nonstationary waveform distortions in electric power systems are mainly related to phase-locked loop (PLL) techniques.

An initial suggestion to the application of PLL-based methods in electrical power systems is presented in [58], where a good tutorial addressing capabilities of an enhanced version of PLL (EPPL) [59] is developed and the analysis of time-varying harmonics through this enhanced versions is also suggested and exemplified. In [60], a direct application of the suggestion done in [58] is used to develop a processing unit to 
track parameters of a single harmonic component. It is claimed that the unit proposed is capable of supporting noise and adapting to the variations in the frequency of the harmonic component in analysis. The results make it clear the superiority of the method over a conventional DFT-based approach, but issues related to slow transient response time and accuracy in the presence of noise are present. Another application of EPLL is proposed in [61], where a parametric filter bank is used to decompose a multi-component signal into a group of frequency bands that are then analyzed by specific EPLL units responsible for estimating the parameters of each of the harmonics in analysis. Frequency, amplitude and interharmonics may be tracked. The results presented show an improvement in the transient response time if compared to the proposed in [60], but convergence time is still a problem, although the related computational effort is reduced. In [62], a new version of the proposed method presented in [61] is shown. Such a new version is concerned with the concept of apparent frequency and undersampling and its application shows an accuracy quite similar to earlier version and an improvement in both transient response time and computational burden, although the transient issue is still present.

Besides PLL approaches, proposed methods based on filters and classic filter banks (CBF) are also reported and some improvements were reached. In [63], a technique based on the application of signal mixing and filtering operations is proposed. It is employed to track amplitude and frequency in slow time-varying waveform and its results show its capability to correctly track parameters of a pure sinusoidal waveform. However, the technique has limitations when applied to the analysis of waveform with harmonic distortions and inherits problems from the application of digital filters such a delayed response, phase shift, heavy computational effort, and frequency spillover. A bank of filters that addresses the issue of frequency spillover is proposed in [64]. This work employs a power-symmetric filter bank, a single-sideband modulation technique and downsampling to suggest an analysis structure whose application in test signals reveals an accurate tracking response at the cost of a high computational effort and the incapacity to handle both frequency drift and interharmonics. The method is also capable of tracking DC components, but suffers from a significant delay in response when step-like changes are present in the analysed signal.

Others classes of signal processing techniques present are the adaptive notch filters (ANF) [65] and the empirical mode decomposition (EMD) approaches. An application of ANF in power system is presented in [66], where a method to detect and extract time-varying harmonics is proposed as a tool for selective harmonic elimination techniques. The proposed method suggests the use of an ANF unity to track the frequency, amplitude and phase of a single harmonic and then the employment of $n$ unities in parallel to track the parameters of $\mathrm{n}$ harmonics. Results reported indicate that the technique is capable of tracking step-like changes in amplitude with a response within 2 cycles of the fundamental frequency, but tests concerning variations in frequency and phase are omitted and thus a complete insight on the capabilities of the method is not possible. Others studies and proposed methods regarding the performance of ANF-based methods that aim to handle non-stationary multi-component waveforms and that are not related to the subject covered by this paper may be found in [67]-[71]. EMD approaches comprise the references [35] and [72], that have the purpose of improving the weak capacity of the original EMD [5] to separate components whose frequencies lie within a same octave. Both the proposed methods reach its purposes, but the results shown have poor accuracy. In addition to the limitation addressed by the cited references, the EMD is a data-driven technique which employs an extensive application algorithm, requires previous analysis of the main characteristics of the signal and still has constrains related to the generation of its so-called intrinsic mode functions (IMF) [35].

Table 5 shows a summary of the proposed methods related to each of the signal processing techniques analyzed.

TABLE 5

Signal PROCESSING TeCHNIQUES

\begin{tabular}{|c|c|c|}
\hline Technique & Capabilities & Characteristics \\
\hline PLL & \multirow[t]{3}{*}{$\begin{array}{l}\text { track individual } \\
\text { waveforms of } \\
\text { harmonic } \\
\text { components }\end{array}$} & $\begin{array}{l}\text { - delayed response in transients; } \\
\text { - able of track interharmonics; } \\
\text { - non-susceptible to noise; } \\
\text { - embedded tracking of frequency. }\end{array}$ \\
\hline CFB & & $\begin{array}{l}\text { - accurate; } \\
\text { - able to track DC components; } \\
\text { - susceptible to interharmonics; } \\
\text { - susceptible to noise; } \\
\text { - susceptible to frequency drift; } \\
\text { - high computational effort. }\end{array}$ \\
\hline ANF & & $\begin{array}{l}\text { - delayed response in transients; } \\
\text { - non-susceptible to noise; } \\
\text { - susceptible to interharmonics; } \\
\text { - high computational effort. }\end{array}$ \\
\hline EMD & $\begin{array}{l}\text { track IMF } \\
\text { components }\end{array}$ & $\begin{array}{l}\text { - complex application algorithm; } \\
\text { - poor accuracy; } \\
\text { - requires a previous study of the } \\
\text { signal to be analyzed; } \\
\text { - still not suitable for an automated } \\
\text { application. }\end{array}$ \\
\hline
\end{tabular}

\section{E. Parametric and parametric-like approaches}

Proposed applications of parametric and parametric-like methods for tracking non-stationary distortions in power systems are mainly related to Prony, ESPRIT and MUSIC techniques. Some of these approaches has been successfully applied to the spectral estimation of stationary signals [73] and have some advantages over the DFT such a more accurate response and the capability of precisely measuring interhamonics [74]. Its extensions to the non-stationary scenario employ the assumption that a signal to be analyzed may be divided into a group of consecutive windows and that within each of these segments the data may be treated as being stationary [75]-[78]. All the methods analyzed are more computationally intensive than conventional DFT-based approaches. In [75], a Prony-based method used to measure non-stationary harmonic currents is presented. The reference also reports a set of tests where the tracking of waveforms is done in the presence of various types of amplitude variations, with good results concerning accuracy and some response 
time limitations when in the presence of stepwise variations. Another proposed method employing a Prony-based method is done in [76], but this time the Prony approach is compared to a rootMusic-based approach and both are applied to the analysis of actual waveforms of an arc furnace. It is stated by the reference that the results of both methods are quite similar and better than the ones obtained from the application of a STFT to the same waveforms. One third employment of a Prony-based method in comparison to another parametric technique, the ESPRIT, is presented in [77], and again the results of both methods are similar and also better than a DFTbased approach. The ESPRIT technique is again employed in [78], where the study of time-varying waveforms in a traction system is developed and the results reported are still better than the ones obtained by the application of a conventional DFT method.

Examples of other parametric methods for handling nonstationary distortions but that are not applied to waveforms in power systems may be found in [43], [52], [79], [80].

\section{F. Artificial Intelligence}

Methods based on concepts and techniques employed in the area of artificial intelligence and whose purpose is to handle non-stationary waveform distortions in electric power systems are restricted to the methods presented in [81]-[83]. In [81], a harmonic estimation method based on an adaptive neural network structure known as Adaline is proposed. The proposed technique, which received the designation of Fourier Linear Combiner (FLC), employs a model of signal similar to the one used by the DFT but with additive noise. Tests concerning its traceability of harmonics with sinusoidal frequency variation are reported in company with results that expose a good accuracy and a computational cost lower than early KF-based methods, but susceptibility on frequency drift is also reported and a heavy dependence on the parameters of the neural network employed was made clear. In [82], an improvement of the FLC is proposed by means of the aggregation of an Extended Kalman filter (EKF) so the initial susceptibility on frequency drift is suppressed. Within this method, the EKF is used to estimate the frequency of the signal and then the obtained frequency is used as an input parameter to the FLC, so the estimation of amplitude and phase may take in account the actual frequency of the signal in analysis. As a result, the proposed method is capable of estimating frequency, amplitude and phase, and still requires a lower computational effort than a conventional KF-based approach with a fixed gain matrix. However, in all reported tests the convergence time of the estimation is considerably large and during the convergence interval relevant accuracy issues may be noted. In [83], the application of classic optimization techniques usually employed in neural networks are assumed to the estimation of time-varying harmonics trough a method which employs a sliding time window and also an adaptive approach. The results report a good capability to correctly track stepwise variations in harmonics and the adaptation is reached within one cycle of the fundamental, but significant accuracy problems do exist.

\section{CONCLUSIONS}

This paper has presented a bibliographical survey of techniques aimed at analyzing non-stationary waveforms in electrical power systems.

It was identified that the related methods presented in literature are based on a variety of techniques, and since each of these techniques have specific characteristics, each of the analyzed methods bring different functions, advantages, and limitations.

Some proposed methods based on specific families of timefrequency representations and specific concepts are suitable to the measurement of time-varying waveforms, while others based on different time-frequency representations are more suitable to the analysis of power quality events, as are, for example, methods that employ the $\mathrm{S}$ transform and the Wavelet transform. Methods based on signal processing and state estimation techniques as Kalman filters, classical filter banks, phase-locked loops, adaptive notch filters, and some variations of the DFT are capable of decomposing and tracking non-stationary multi-component signals. These methods have the more significant results, but, as the other methods analyzed, each of them have specific and significant limitations that must be taken in account and that prevent them from being employed as definitive methods for the analysis of non-stationary waveforms in electrical power systems.

In order to provide a quantitative comparison between the proposed methods with better results among the ones analyzed, a paper encompassing a study of its performance is in preparation.

\section{REFERENCES}

[1] A. Kusko and M.T. Thompson, Power Quality in Electrical Systems, 1st ed., New York, United States: McGraw-Hill, 2007

[2] G. Carpinelli, P. Ribeiro, and A. Testa, "Probabilistic and TimeFrequency Aspects of Time Varying Waveforms in Power Systems," in Proc. PSCE'06, 2006, p. 246- 251.

[3] G. Carpinelli, P. Ribeiro, and A. Testa, "Time-varying harmonics of single-phase nonlinear appliances," in Proc. PESWM'02, 2002, p. 10661071.

[4] Y.N. Chang, Y.C. Hsieh, and C.S. Moo, "Truncation effects of FFT on estimation of dynamic harmonics in power system," in Proc. PowerCon'00, 2000, vol.3, p. 1155-1160.

[5] N.E. Huang, Z. Shen, S.R. Long, M.L. Wu, H.H. Shih, Q. Zhen, N.C. Yen, C.C. Tung, and H.H. Liu, "The empirical mode decomposition and the Hilbert spectrum for nonlinear and non-stationary time series analysis," in Proc. Royal Soc. London A, 1998, vol.454, p. 903-995.

[6] M. Wang and Y. Sun, "A practical, precise method for frequency tracking and phasor estimation," IEEE Trans. Power Delivery, vol. 19, pp. 1547-1552, Oct. 2004.

[7] Y. Baghzouz, R.F. Burch, A. Capasso, A. Cavallini, A.E. Emanuel, M. Halpin, A. Imece, A. Ludbrook, G. Montanari, K.J. Olejniczak, P.F. Ribeiro, S. Rios-Marcuello, L. Tang, R. Thaliam, and P. Verde, "Timevarying harmonics: Part I - Characterizing measured data," IEEE Trans. Power Delivery, vol. 13, pp. 938-944, Jul. 1998.

[8] P.J. Masson, P.M. Silveira, C. Duque, and P.F. Ribeiro, "Fourier series: Visualizing Joseph Fourier's imaginative discovery via fea and timefrequency decomposition," in Proc. ICHQP'08, 2008, p.1-5.

[9] J.W. Cooley and J.W. Tukey, "An Algorithm for the Machine Calculation of Complex Fourier Series," Mathematics of Computation, vol. 19, pp. 297-301, Oct. 1965.

[10] P.F. Ribeiro, "A Novel Way For Dealing With Time-Varying Harmonic Distortions: The Concept of Evolutionary Spectra," in Proc. PES'03, 2003, vol.2, p. 1153.

[11] M.B. Priestley, "Evolutionary Spectra and Non-stationary Processes," $J$. Royal Stat. Soc. B, vol. 27, pp. 204-237, 1965. 
[12] A.S. Kayhan, A. El-Jaroudi, and L.F. Chaparro, "Data-adaptive evolutionary spectral estimation," IEEE Trans. Signal Processing, vol. 43, pp. 204-213, Jan. 2005.

[13] C.S. Moo, Y.N. Chang, and P.P. Mok, "A digital measurement scheme for time-varying transient harmonics," IEEE Trans. Power Delivery, vol. 10, pp. 588-594, Apr. 1995.

[14] T.A.C.M. Claasen and W.F.G. Mecklenbräuker, "The Wigner Distribution - A Tool for Time-Frequency Signal Analysis, Part II: Discrete-time Signals," Philips Journal of Research, vol. 35, pp. 276300, 1980.

[15] F. Hlawatsch and G.F. Boudreuax-Bartels, "Linear and quadratic timefrequency signal representations," IEEE Signal Processing Magazine, vol. 9, pp.21-67, Apr. 1992.

[16] L. Cohen, "Time-Frequency Distributions-A Review," in Proc. IEEE, 1989, vol. 77, pp. 941-981.

[17] D. Jones and T. Parks, "A high resolution data-adaptive time-frequency representation," IEEE Trans. Acoustics, Speech and Signal Processing, vol. 38, pp. 2127-2135, Dec. 1990.

[18] V.L. Pham and K.P. Wong, "Antidistortion method for wavelet transform filter banks and nonstationay power system waveform harmonic analysis," in Proc. IEE Gener., Transm., Distrib., 2001, p. $117-122$.

[19] H.I. Choi and W.J. Williams, "Improved time-frequency representation of multicomponent signals using exponential kernels," IEEE Trans. Acoustics, Speech and Signal Processing, vol. 37, pp. 862-871, Jun. 1989.

[20] L.L. Scharf, B. Friedlander, and C.T. Mullis, "Time-Varying Spectrum Estimators," in Proc. 31th Asilomar Conference on Signals, Systems and Computers, 1997, vol. 2, pp. 1467-1470.

[21] M. Harashima, L.A. Ferrari, and P.V. Sankar, "Time-frequency representation for time-varying signals using a Kalman filter," in Proc. 29th Asilomar Conference on Signals, Systems and Computers, 1995, vol. 1, pp. 558-563.

[22] W. Roguet, N. Martin, A. Chehikian, "Tracking of frequency in a timefrequency representation," in Proc. Third International Symposium on Time-Frequency and Time-Scale Analysis, 1996, vol. 1, pp. 341-344.

[23] J. Mars, N. Martin, J.L. Lacoume, and M. Dubesset, "Analysis of signals over short time-windows," ACM Journal of Signal Processing, vol. 26, pp. 147-159, 1992.

[24] P.M. da Silveira, C.A. Duque, and P.F. Ribeiro, "Time-Varying Power Harmonic Decomposition using Sliding-Window DFT," in Proc. ICHQP'08, 2008.

[25] P.M. Silveira, C.A. Duque, T. Baldwin, and P.F. Ribeiro, "Sliding window recursive DFT with dyadic downsampling - A new strategy for time-varying power harmonic decomposition," in Proc. PES'09, 2009, vol.1, p. 1-6.

[26] C. Zhao, M. He, and X, Zhao, "Analysis of transient waveform based on combined short time Fourier transform and wavelet transform," in Proc. PowerCon'04, 2004, vol. 2, p. 1122-1126.

[27] S.G. Mallat, "A theory for multiresolution signal decomposition: the wavelet representation," IEEE Trans. Pattern Analysis and Machine Intelligence, vol. 11, pp. 674-693, Jul. 1989.

[28] W. Jianze, J. Yanchao, W. Fei, and R. Qiwen, "New method for transient harmonics measurement based on wavelet transform," in Proc. IECON' '98, 1998, vol. 2, p. 636-639.

[29] P.M. Silveira, M. Steuner, and P.F. Ribeiro, "Using Wavelet Decomposition for Visualization and Understanding of Time-Varying Waveform Distortion in Power Systems," in VII CBQEE, Brazil, Aug. 2007.

[30] S. Huang and C. Hsieh, "Visualizing time-varying power system harmonics using a Morlet wavelet transform approach," Electric Power Systems Research, vol. 58, pp. 81-88, Jun. 2001.

[31] R.G. Stockwell, L. Mansinha, and R.P. Lowe, "Localization of the Complex Spectrum: The S Transform," IEEE Trans. Signal Processing, vol. 44, pp. 998-1001, Apr. 1996.

[32] P. K. Dash, B. K. Panigrahi, and G. Panda, "Power Quality Analysis Using S-Transform," IEEE Trans. Power Delivery, vol. 18, pp. 406411, Apr. 2003.

[33] M.V. Chilukuri and P.K. Dash, "Multiresolution S-transform-based fuzzy recognition system for power quality events," IEEE Trans. Power Delivery, vol. 19, pp. 323-330, Jan. 2004.

[34] S.J.Huang, C.L. Huang, and C.T. Hsieh, "Application of GABOR transform technique to supervise power system transient harmonics," in Proc. IEE Gener., Transm., Distrib., 1996, p. 461-466.
[35] N. Senroy, S. Suryanarayanan, and P.F. Ribeiro, "An Improved HilbertHuang Method for Analysis of Time-Varying Waveforms in Power Quality," IEEE Trans. Power Systems, vol. 22, pp. 1843-1850, Nov. 2007.

[36] J. Xu, N. Senroy, S. Suryanarayanan, and P.F. Ribeiro, "Some Techniques for the Analysis and Visualization of Time-varying Waveform Distortions," in 38th North American Power Symposium, 2006, vol. 1, pp. 257-261.

[37] F. Zhang, G. Bi, Y.Q. Chen, and Y. Zeng, "Harmonic transform," in Proc ICASSP'01, 2001, vol. 6, p. 3537-3540.

[38] R.B. Pachori and P. Sircar, "Analysis of multi-component non-stationary signals using Fourier-Bessel Transform and Wigner Distribution," in Proc 14th European Signal Processing Conference, 2006.

[39] G. Wang, "Time-varying discrete-time signal expansions as timevarying filter banks," IET Signal Processing, vol. 3, pp. 353-367, Sep. 2009.

[40] I. Sodagar, K. Nayebi,and T.P. Barnwell, "Time-varying filter banks and wavelets," IEEE Trans. Signal Processing, vol. 42, pp. 2983-2996, Nov. 1994.

[41] U.K. Laine, "Famlet, to be or not to be a wavelet?," in Proc. IEEE-SP International Symposium, 1992, pp. 335-338.

[42] R.G. Brown and P.Y.C. Hwang, Introduction to Random Signals and Applied Kalman Filtering, 3rd ed., New York, United States: Wiley, 1996.

[43] V.G. Asutkar, B.M. Patre, T.K. Basu, "Kalman Filter Approach for Identification of Linear Fast Time-Varying Processes," in Proc. INCACEC 2009, 2009, pp. 1-5.

[44] A.A. Girgis and T.L.D. Hwang, "Optimal Estimation Of Voltage Phasors And Frequency Deviation Using Linear And Non-Linear Kalman Filtering: Theory And Limitations," IEEE Trans. Power Apparatus and Systems, vol. 103, pp. 2943-2951, Oct. 1984.

[45] A.A. Girgis, W.B. Chang, and E.B. Makram, "A digital recursive measurement scheme for online tracking of power system harmonics," IEEE Trans. Power Delivery, vol. 6, pp. 1153-1160, Jul. 1991.

[46] P.K. Dash, A.K. Pradhan, and G. Panda, "Frequency estimation of distorted power system signals using extended complex Kalman filter," IEEE Trans. Power Delivery, vol. 14, pp. 761-766, Jul. 1999.

[47] D. Bak, M. Michalik, and J. Szafran, "Application of Kalman filter technique to stationary and nonstationary state observer design," in Proc. IEEE Bologna Power Tech Conference, 2003, vol. 3, p. 6.

[48] A.M. Stankovic, H. Lev-Ari, and M.M. Perisic, "Analysis and implementation of model-based linear estimation of dynamic phasors," IEEE Trans. Power Systems, vol. 19, pp. 1903-1910, Nov. 2004.

[49] R. Aghazadeh, and H. Lesani, M. Sanaye-Pasand, and B. Ganji, "New technique for frequency and amplitude estimation of power system signals," in Proc. IEE Gener., Transm., Distrib., 2005, p. 435-440.

[50] C.I. Chen, G.W. Chang, R.C. Hong, and M.H. Li, "Extended Real Model of Kalman Filter for Time-Varying Harmonics Estimation," IEEE Trans. Power Systems, vol. 25, pp. 17-26, Jan. 2010.

[51] M.S. Arulampalam, S. Maskell, N. Gordon, and T. Clapp, "A tutorial on particle filters for online nonlinear/non-Gaussian Bayesian tracking," IEEE Trans. Signal Processing, vol. 50, pp. 174-188, Feb. 2002.

[52] Y. Zheng, Z. Lin, and Y. Ma, "Recursive blind identification of nonGaussian time-varying AR model and application to blind equalisation of time-varying channel," in Proc. IEE Vision, Image and Signal Processing, 2001, p. 275-282.

[53] C. Dubois, M. Davy, and J. Idier, "Tracking of time-frequency components using particle filtering," in Proc ICASSP'05, 2005, vol. 4, p. 9-12.

[54] S.A. Soliman, A.M. Al-Kandari, K. El-Nagar, and M.E. El-Hawary, "New dynamic filter based on least absolute value algorithm for on-line tracking of power system harmonics," in Proc. IEE Gener., Transm., Distrib., 1995 , vol. 142 , p. 37-44.

[55] G. S. Christensena and S. A. Solimanb, "Optimal filtering of linear discrete dynamic systems bad on least absolute approximation," Automatica, vol. 26, pp. 389-395, Mar. 1990.

[56] C. Tao, D. Shanxu, and C. Changsong, "An efficient frequency and amplitude tracking method for real-time power quality monitoring," in Proc. IPEMC'09, 2009, p. 2459-2463.

[57] S. Andreon, E.E. Yaz, and K.J Olejniczak, "Reduced-order estimation of power system harmonics using set theory," in Proc. 1999 IEEE International Conference on Control Applications, 1999, vol. 1, pp. 820825 . 
[58] M. Karimi-Ghartemani and M.R. Iravani, "A Nonlinear Adaptive Filter for Online Signal Analysis in Power Systems: Applications," IEEE Trans. Power Delivery, vol. 17, pp. 617-622, Apr. 2002.

[59] M. Karimi-Ghartemani and M.R. Iravani, "A new phase-locked loop (PLL) system," in Proc. 44th IEEE 2001 Midwest Symposium on Circuits and Systems, 2001, vol. 1, pp. 421-424.

[60] M. Karimi-Ghartemani and M.R. Iravani, "Measurement of Harmonics/Inter-harmonics of Time-Varying Frequencies," IEEE Trans. Power Delivery, vol. 20, pp. 23-31, Jan. 2005.

[61] J.R. Carvalho, P.H. Gomes, C.A. Duque, M.V. Ribeiro, and J. Szczupak, "PLL Based Multirate Harmonic Estimation," in IEEE Power Engineering Society General Meeting, 2007, vol. 1, pp. 1-6.

[62] J.R. Carvalho, C.A. Duque, M.V. Ribeiro, A.S. Cerqueira, T.L. Baldwin, and P.F. Ribeiro, "A PLL-Based Multirate Structure for Time-Varying Power Systems Harmonic/Interharmonic Estimation," IEEE Trans. Power Delivery, vol. 24, pp. 1789-1800, Oct. 2009.

[63] M. D'Apuzzo and M. D'Arco, "Frequency and Amplitude Tracking of Time-Varying Harmonics and Interharmonics in Power Systems," in Proc. IMTC 2006, 2006, p. 1614-1619.

[64] C. Duque, P.M. Silveira, T. Baldwin, and P.F. Ribeiro, "Novel method for tracking time-varying power harmonic distortions without frequency spillover," in IEEE Power and Energy Society General Meeting, 2008, pp. 1-6.

[65] L. Hsu, R. Ortega, and G. Damm, "A globally convergent frequency estimator," IEEE Trans. Autom. Control, vol. 44, pp 698-713, Apr. 1999.

[66] D. Yazdani, A. Bakhshai, G. Joos, and M. Mojiri, "A real-time selective harmonic extraction approach based on adaptive notch filtering," in Proc. IEEE International Symposium on Industrial Electronics, 2008, pp. 226-230.

[67] S.M. Savaresi, "Frequency estimation of harmonic signals subject to step-wise variations using notch filters and funnel filters," in Proc. 36th IEEE Conference on Decision and Control, 1997, vol. 2, pp.1694-1699.

[68] M. Mojiri and A.R. Bakhshai, "Estimation of n Frequencies Using Adaptive Notch Filter," IEEE Trans. Circuits and Systems II: Express Briefs, vol. 54, pp. 338-342, Apr. 2007.

[69] M. Mojiri, M. Karimi-Ghartemani, and A.R. Bakhshai, "Time-Domain Signal Analysis Using Adaptive Notch Filter," IEEE Trans. Signal Processing, vol. 55, pp. 85-93, Jan. 2007.

[70] M. Karimi-Ghartemani, M. Mojiri, and A.R. Bakhshai, "A Technique for Extracting Time-Varying Harmonics Based on an Adaptive Notch Filter," in Proc. 2005 IEEE Conference on Control Applications, 2005, pp. 624-628.

[71] T. Kwan and K. Martin, "Adaptive detection and enhancement of multiple sinusoids using a cascade IIR filter," IEEE Trans. Circuits and Systems, vol. 36, pp. 937-947, Jul. 1989

[72] N. Senroy and S. Suryanarayanan, "Two Techniques to Enhance Empirical Mode Decomposition for Power Quality Applications," in IEEE Power Engineering Society General Meeting, 2007, vol.1, pp.1-6.

[73] S.L. Marple Jr., "A tutorial overview of modern spectral estimation," in Proc ICASSP'89, 1989, vol. 4, p. 2152-2157.

[74] Z. Leonowicz, T. Lobos, and J. Rezmer, "Advanced spectrum estimation methods for signal analysis in power electronics," IEEE Trans. Industrial Electronics, vol. 50, pp. 514-519, Jun. 2003.

[75] T. Nakajima, M. Tamura, and E. Masada, "Compensation of nonstationary harmonics using active power filter with Prony's spectral estimation," in Proc. 19th Annual IEEE Power Electronics Specialists Conference, 1988, vol. 2, pp. 1160-1167.

[76] A. Bracale, G. Carpinelli, D. Lauria, Z. Leonowicz, T. Lobos, and J. Rezmer, "On some spectrum estimation methods for analysis of nonstationary signals in power systems. Part II. Numerical applications," in 11th International Conference on Harmonics and Quality of Power, 2004, pp. 260-265.

77] A Bracale, G Carpinelli, $\mathrm{T}$ Lobos, $\mathrm{Z}$ Leonowicz, and J Rezmer, "Evaluation of compensation devices of DC arc furnaces using advanced spectrum estimation methods," in Proc. 15th Power Systems Computation Conference, 2005, section 4, paper 5, p. 1.

[78] Z. Leonowicz and T. Lobos, "Analysis of Traction System TimeVarying Signals using ESPRIT Subspace Spectrum Estimation Method," in Proc. IECON 2006, 2006, p. 3424-3427.

[79] Y. Grenier, "Time-dependent ARMA modeling of nonstationary signals," IEEE Trans. Acoustics, Speech and Signal Processing, vol. 31, pp. 899-911, Aug. 1983.
[80] A.I. Al-Shoshan, "Identification of a linear, time-varying system using the time-varying higher-order statistics," in 6th International Conference on Signal Processing, 202, vol. 1, pp. 243-246.

[81] P.K. Dash, D.P. Swain, A. Routray and A.C. Liew, "Harmonic estimation in a power system using adaptive perceptrons," in Proc. IEE Generation, Transmission and Distribution, 1996, vol. 143, p. 565-574.

[82] P.K. Dash, A.K. Pradhan, G. Panda, R.K. Jena, and S.K. Panda, "Online tracking of time varying harmonics using an integrated extended complex Kalman filter and Fourier linear combiner," in IEEE Power Engineering Society Winter Meeting, 2000, vol. 3, pp. 1575-1580.

[83] S. Osowski, "Neural network for estimation of harmonic components in a power system," in Proc. IEE Generation, Transmission and Distribution, 1992, vol. 139, p. 129-135.

\section{BIOGRAPHIES}

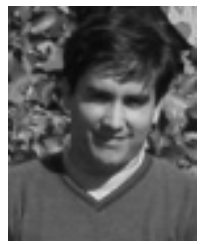

Rodrigo de Paula Rodrigues received his BS degree in Computer Engineering from the Universidade Federal de Itajubá, Minas Gerais, Brazil, in 2006, and his M.Sc. degree in Electrical Engineering from the same school in 2009. Presently, he has developed studies in power quality as a Ph.D. student member at Power Quality Study Group (GQEE). His areas of interest are Nonlinear Loads, Nonstationary Harmonics, Signal Processing, and Power Quality Instrumentation.

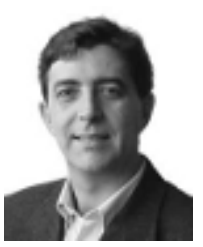

Paulo Márcio da Silveira received his BSEE and MSc degrees from the Federal Engineering School of Itajubá (EFEI), Brazil, in 1984 and 1991, respectively, and his Ph.D. degree in electrical engineering from Federal University of Santa Catarina (UFSC), Brazil, in 2001. Since 1992 he is Professor at Itajubá Federal University, where he is also the Power Quality Study Group (GQEE) Coordinator. His research interest includes Power System Protection, Power Quality, and Signal Processing for Instrumentation.

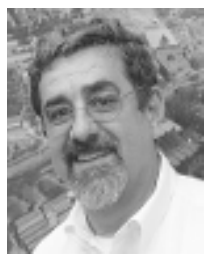

Paulo F. Ribeiro received a BS in Electrical Engineering from the Universidade Federal de Pernambuco, Recife, Brazil, completed the Electric Power Systems Engineering Course with Power Technologies, Inc. (PTI) 1 , and received the Ph.D. from the University of Manchester, Manchester-UK. Presently, he is a Professor of Engineering at Calvin College, Grand Rapids, Michigan, USA. Ribeiro is active in IEEE, CIGRE and IEC working groups on power quality. He is Registered Professional Engineer in the State of Iowa. 